\title{
Study the Effect of Copper Oxide Nanoparticles on Reduce Crude Oil
}

\author{
Sarah T. Shakir ${ }^{\text {** }}$ and Husham Al-Tameemi ${ }^{a}$ \\ ${ }^{a}$ Chemical Engineering Department -Faculty of Engineering - University of Al-Qadisiyah-Iraq
}

\section{A R T ICLE INFO}

\section{Article history:}

Received 27 August 2019

Received in revised form 23 September 2019

Accepted 30 September 2019

\author{
Keywords: \\ Reduce Crude oil \\ Viscosity reduction \\ Drag reduction \\ Copper oxide Nanoparticles
}

\begin{abstract}
A B S TR A C T
In the transportation of fluid, the drag reducers in pipeline are important parameters because of drag reduction increased the ability of pump fluid when adding small amounts of additive to fluid. The frictional pressure loss in pipes is waste energy and it very costly so the drag reducing minimizes flow turbulence, reduces the costs of energy and increases throughput. The transportation of reducing crude oil is very difficult and needs some treatment to improve its transportation and this is because of its high viscosity. The purpose of this research is to study the effect of nanoparticles of copper oxide on viscosity of R.C. and other parameters when transport it through pipes. This research investigated the viscosity, pressure drop and other parameters in three pipes $(0.0127,0.01905$ and $0.0254 \mathrm{~m})$ I.D. with different concentrations $(0.00625$, $0.0125,0.01875,0.025$ and $0.0375(\mathrm{gm} / \mathrm{L}) \mathrm{w} / \mathrm{v})$ at $50{ }^{\circ} \mathrm{C}$ and the flow rate is $50 \%$ of maximum. The results show that the performance of the drag reduction is much better in the larger pipes diameter than the smaller one. Also, the CuO NP's effect on R.C. viscosity and the maximum viscosity deviation is about $4 \%$. In Addition to CuO NP's to R.C. has reduced the \%Dr, pressure drop and shear stress.
\end{abstract}

\section{Introduction}

Reduced crude oil (black oil) (R.C.), is a product that is drawn from the bottom of the atmospheric distillation tower and has a boiling point above $425^{\circ} \mathrm{C}$. Reduced crude oil is the feedstock of vacuum distillation and the objective of vacuum distillation is fractionate reduce crude oil to derivatives and used it as base oil [1]. R.C. contains heavy components so that it is difficult to transport it, many techniques are used to improve it, and one of them is by adding different quantities of chemical additives like surfactant, polymer, and fiber [2,3].

\subsection{Reducing viscosity when adding particles Structure}

The using metal particles as a viscosity reducer for heavy oil/bitumen are contradicted the Einstein's [4] equation which relates the viscosity of dispersion medium $(\mu \mathrm{o})$ and viscosity of dilute liquid suspension for noninteracting uniform of solid spheres $(\mu)$ :-

$\mu=\mu_{\mathrm{o}}(1+2.5 \phi)$

If it does not consider any interaction between the oil and particles, which is one of the assumptions of this equation the contradiction may arise. However, the effect of interactions could not be major to overcome the increase of viscosity because of the physical effects such as given by Eq.1. For that reason there will be an optimum concentration of the particles at which the effect of reactions is maximum which gives maximum viscosity reduction as a result of the applied particles metal type [5]. The revolution of nanotechnology science has attracted great attention

\footnotetext{
* Corresponding author.

E-mail address: shahadmahdi2015@gmail.com (Shahad Al-Obaidi)
} 


\begin{tabular}{|c|c|c|c|}
\hline \multicolumn{4}{|c|}{ Nomenclature } \\
\hline$\% \mathrm{Dr}$ & Percentage drag reduction & $u$ & velocity of R.C. inside the pipe \\
\hline$D$ & Diameter of pipe (m). & $\Delta P$ & Pressure drop \\
\hline$f$ & Friction factor & $\Delta \mathrm{Pb}, \Delta \mathrm{Pa}$ & Pressure drop before and after adding Nano additives. \\
\hline $\mathrm{L}$ & Length of pipe $(\mathrm{m})$. & & \\
\hline NPs & Nanoparticles & \multicolumn{2}{|c|}{ Greek symbols } \\
\hline R.C. & Reduce crude oil & $\rho$ & Density of R.C \\
\hline $\operatorname{Re}$ & Reynold number & $\tau$ & Shear stress \\
\hline Sp.gr & Specific gravity & $\tau_{\mathrm{w}}$ & Wall shear stress (bar). \\
\hline
\end{tabular}

for its important role in many applications in the oil \& gas industry, for example, sensing or imaging, enhanced oil recovery, gas mobility control and other applications [6-8]. Nanoparticles could be defined that are the materials that have one dimensioned range from 1 to $100 \mathrm{~nm}$. Also, submicron particles $(<1000 \mathrm{~nm})$ could be considered nanoparticles [7, 913]. A number of special properties that nanoparticle reveal corresponding to the bulk material. Such as, the bending copper's bulk (wire, ribbon, etc.) take place with movement of copper atoms or clusters at approximately 50 $\mathrm{nm}$ scale. Nano Copper smaller than the $50 \mathrm{~nm}$ are considered as super hard materials that do not display the same flexibility such as bulk copper $[14,15]$. NPs have a very high surface area relative to volume ratio [14]. Many researchers examine the effect of NPs on viscosity by using different metal oxides and with a different technique. It has been observed that reduction of heavy oil viscosity was because of high temperature effect besides a series of chemical reactions known as aqua-thermolysis and these reaction change the physical properties [12].

Clark et al. [11] discovered that the heavy oil viscosity is more reduced when aqueous metal salt is added into the process in comparison to Steamonly experiments. $\mathrm{Li}$ et al. [13] found that reduced viscosity, resin and asphaltene content of extra-heavy oil efficiently and that because of the effect of a Nano nickel catalyst in viscosity reduction of Liahoextra-heavy oil by aqua-thermolysis reaction. Hamedi Shokrlu and Babadagli [5] studied the effect of nanosized metals on viscosity reduction of heavy oil/bitumen during thermal applications. Haroun et al. [16] discovered that copper oxide are able to enhance injection water viscosity. Ehsanollah Ettefaghi et.al [17] concluded that no Appreciable change in the oil's viscosity with respect to the engine oil without $\mathrm{CuO}$ nanoparticles.

Fabian Bjørnseth [18] observed that no viscosity reduction occur-ring when added $\mathrm{Cu}$ nanoparticles to heavy oil at different concentrations and temperatures. Srinivasan and Shah [19] were found that nanoparticles are definitely displayed ability for improving reservoir specific heat and thermal conductivity, as well their ability for enhancing density and viscosity of treatment fluids. S. Afzal et.al. [20] found that addition of $\mathrm{CuO}$ nanoparticles to heavy oil has increased the viscosity at different concentrations at $50^{\circ} \mathrm{C}$. Hascakir et al. [21] investigated the effect of micron sized iron particles on heavy oil viscosity without steam treatment. Chen et al. [22] studied the effect of nano-keggin-K3PMo12O40 on viscosity reduction in catalytic aqua-thermolysis of heavy oil and found that it changes in oxygen-containing groups essentially during the catalytic aquathermolysis. The objectives of this research study the effect of copper oxide nanoparticles on R.C. viscosity, drag reduction and its effect on transportation R.C. in pipelines.

\section{Description of the flow system}

The system consists of three pipes with $0.0127,0.01905$ and $0.0254 \mathrm{~m}$ inside diameter with a length of $6 \mathrm{~m}$ made from carbon steel. As well as each pipe dividing to four Pressure testing sections and the distance between each other is equal to $0.5 \mathrm{~m}$. In addition the flow system contains two tanks, two pumps, flow meter, valves, digital thermometer, pressure gauges, and digital screen. These parts could be seen in Fig. 1.

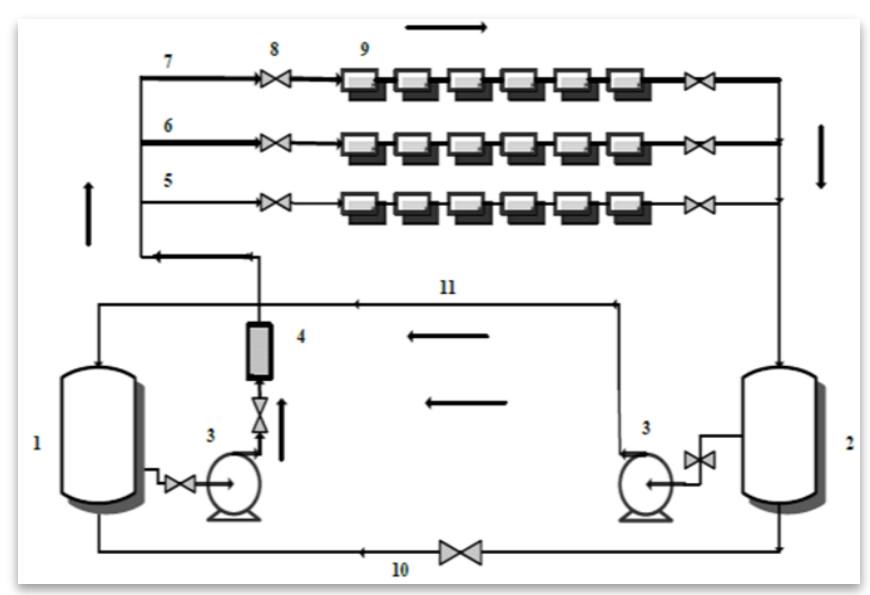

Figure 1. Scheme of the experimental 1-open tank, 2- Receiving tank, 3- Pump, 4- Flow meter, 5, 6, 7- Pipe of 0.5, 0.75 and 1 inch, 8-Valve, 9- Pressure gauge, 10-By-pass pipe, 11- By-pass pipe connect with pump.

\section{Experimental work}

\subsection{Material used:}

\subsubsection{Copper oxide nanoparticles}

The properties of Copper oxide nanoparticles are listed in Table $\mathbf{1}$.

Table 1. Physical Properties of CuO Nano- Powder.

\begin{tabular}{ll}
\hline Chemical Formula & $\mathrm{CuO}$ \\
Appearance (Color) & Black \\
Molecular Weight & $79.545 \mathrm{~g} / \mathrm{mol}$ \\
Average particle size & $\leqslant 50 \mathrm{~nm}$ \\
Appearance $($ Form) & Powder \\
Surface area $\left(\mathrm{m}^{2} / \mathrm{g}\right)$ & $25-40$ \\
\hline
\end{tabular}




\subsubsection{Reduce crude oil}

The R.C. that used is taken from Al-Samawah refinery and the physical properties are shown in Table 2.

Table 2. The physical properties of R.C.

\begin{tabular}{lll}
\hline The Viscosity @ $\mathbf{5 0}^{\circ} \mathbf{C}$ (c.st) & Sp.gr. & API \\
\hline 252 & 0.93 & 20.65 \\
\hline
\end{tabular}

\subsection{Experimental procedure:}

1 - Fill the first tank with a sample of R.C. then run the system.

2 - Pump R.C. through pipes and record the initial readings of pressure for three pipes separately after closed other pipes.

3 - Add the amount of $\mathrm{CuO}$ nanoparticles to the first tank and recycle it for 30 minutes to ensure that the mixture is mixing well.

4. After that repeat step (2) to identify the improvement.

5 - For a continuous process, receiving tank and the second pump are being used to recycle R.C. to the first tank.

\section{4. . Results and Discussion}

Three parameters are studied in this research diameter of pipes, concentration and pressure drop.

\subsection{Effect of Pipe Diameter and Reynolds Number}

Figures (2-6) display the effect of pipe diameter and Reynolds number on $\%$ Dr for different concentrations of $\mathrm{CuO}$ nanoparticles at $50{ }^{\circ} \mathrm{C}$. As can be seen that $\% \mathrm{Dr}$ increased while shear stress decreased as pipe diameter increased at different concentration and this is due to increased area for interaction between R.C. and $\mathrm{CuO}$ nanoparticles [12,23].

The Re, $\%$ Dr, and $\tau$ are calculated by equations below:

For laminar flow, fully developed in pipes $(\operatorname{Re}<2300)$ for different sections areas:-

$$
\begin{aligned}
R e & =\frac{u d}{v} \\
\% D r & =\frac{\Delta P b-\Delta P a}{\Delta P b} * 100 \\
\boldsymbol{\tau}_{w} & =\frac{\boldsymbol{D \Delta P}}{\mathbf{4 L}}
\end{aligned}
$$

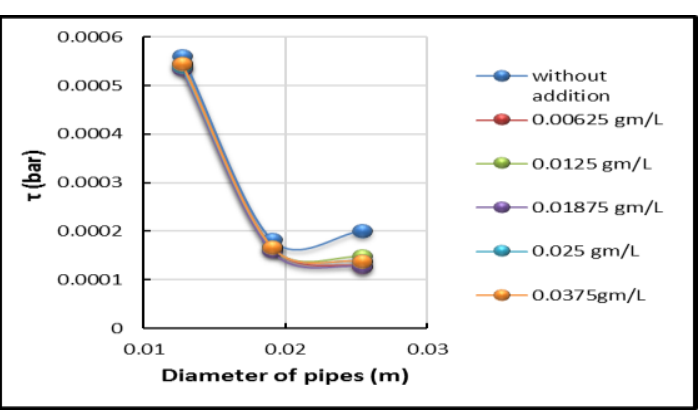

Figure 3. Effect of pipe diameter on shear stress at different concentrations and $50 \mathrm{oC}$.

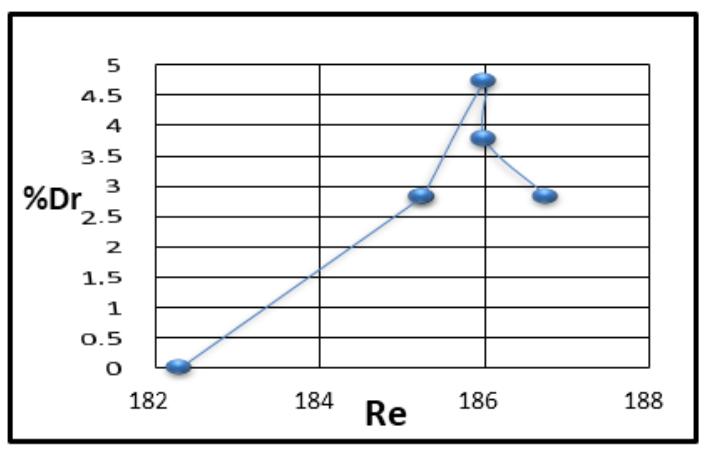

Figure 4. Effect of Re on \% Dr at different concentration at $0.0127 \mathrm{~m} \mathrm{I.D.}$ and $50{ }^{\circ} \mathrm{C}$

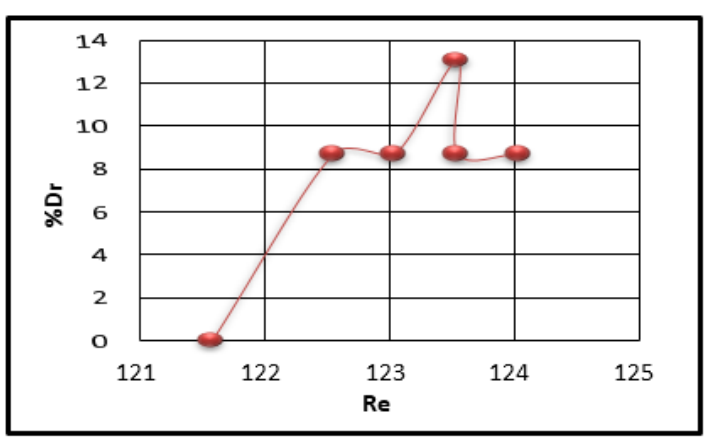

Figure 5. Effect of Re on \% Dr at different concentration at $0.01905 \mathrm{~m}$ I.D. and $50{ }^{\circ} \mathrm{C}$.

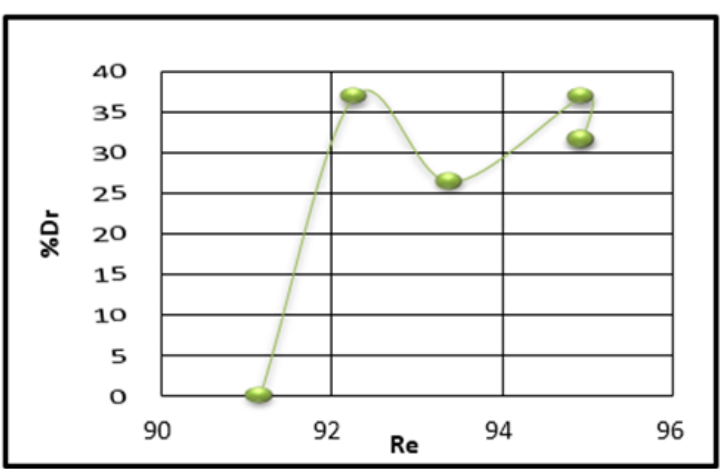

Figure 6. Effect of Re on \%Dr at a different concentration at $0.0254 \mathrm{~m}$ I.D. and $50{ }^{\circ} \mathrm{C}$.

Figure. 2. Effect of pipe diameter on $\mathrm{Re}$ at a different concentration at $50{ }^{\circ} \mathrm{C}$. 
As noticed from three figures above that $\% \mathrm{Dr}$ increased as $\mathrm{Re}$ increased and that because of increasing the degree of turbulence inside the pipe when Re increased which provide best media to the nanoparticles to be more effective. The increasing in \%Dr is occurred due to large eddies that absorb large amount of energy from the main flow, which be present in the pipe of large diameter. But in small pipes, the number of small eddies formed are larger than large eddies formed in large pipes. The small eddies required a large amount of absorbed energy from main flow to overcome the viscosity resistance and after that complete its shape. All small eddies do not absorb the same amount of energy, some of eddies absorb an adequate amount of energy and permit to overcome the resistance of viscosity, while the other absorb insufficient amount of energy and do not be able to overcome viscous resistance and in the end vanish which producing loss in the main flow energy. Because of small eddies which absorbing small amount of energy the \%Dr in the small pipes is lower than in large pipes which do not allow it to overcome the viscosity resistance [12].

\subsection{Effect of concentration}

From figures (7 and 8), it's clear that viscosity and pressure drop are decreased with increased concentration of $\mathrm{CuO}$ nanoparticles and this is because of breakage $\mathrm{C}-\mathrm{S}$ bonds in asphaltene which is unstable and this is happening due exothermic chemical reactions between the oil phase and metal particles. The necessary energy for breaking these bonds could be as long as by exothermic chemical reactions between oil phase and metal particles $[5,21,25]$.

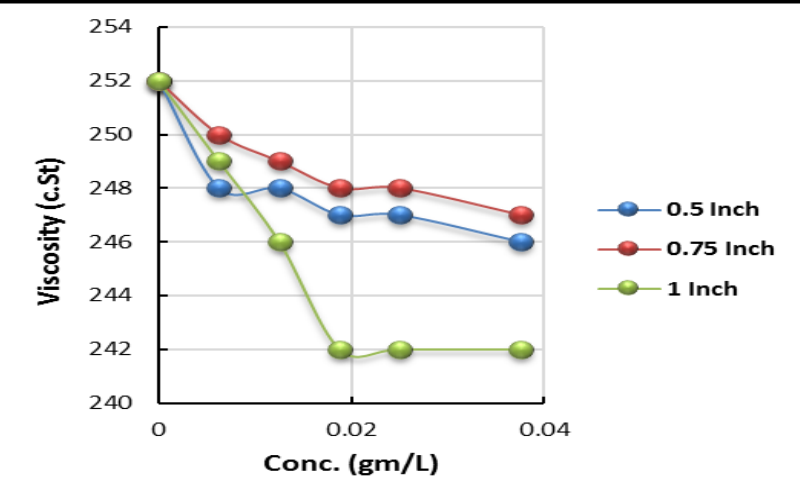

Figure 7. Effect of conc. on viscosity at different pipes and $50^{\circ} \mathrm{C}$.

As can be seen, there is an optimum concentration of $\mathrm{CuO}$ nanoparticles at which the viscosity reduction is maximum. It is noted that the decreasing that occur in pressure drop is a function of additives molecular weight, its concentration and flow rate. The pressure drop is very important as it is directly related to power requirements of the pump or fan for maintaining the flow [26].

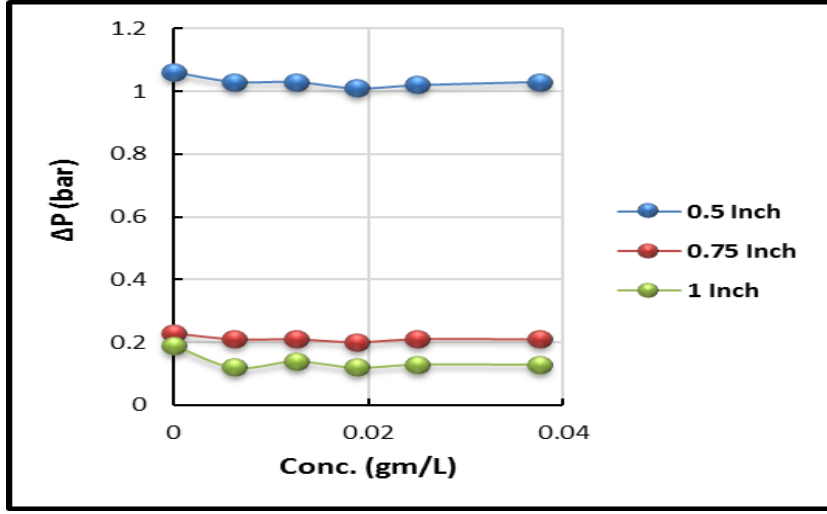

Figure 8. Effect of conc. on pressure drop at different pipes and $50{ }^{\circ} \mathrm{C}$.

\subsection{Friction factor}

Figures (9-11) show the effect of Re on friction factor as can be seen that the friction factor is calculated by two equations and the friction factor that is calculated by eq. 2 . is smaller than in eq. 1 .

$f=\frac{64}{R \mathrm{e}} \quad$ Poisuell's equation

$f=\frac{\Delta p \cdot d / 4 L}{\rho \cdot u^{2} / 2} \quad$ Fanning equation

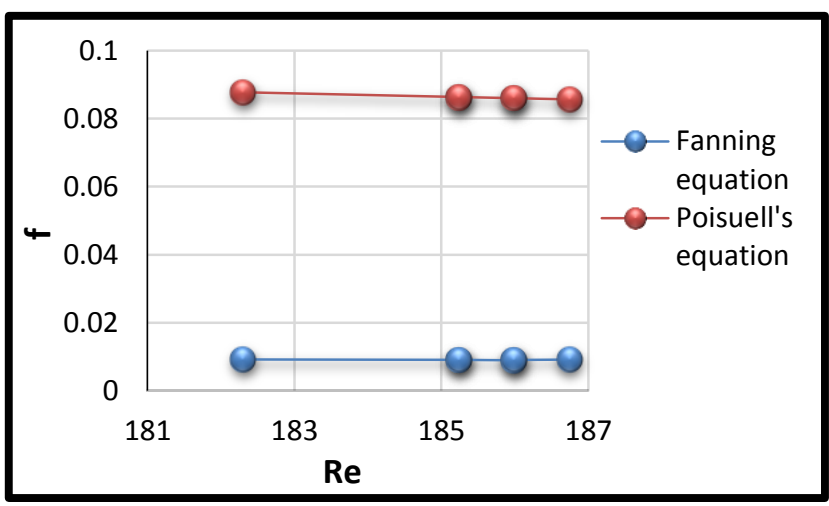

Figure 9. Effect of Re on friction factor at $0.0127 \mathrm{~m} \mathrm{I.D.} \mathrm{and} 50^{\circ} \mathrm{C}$.

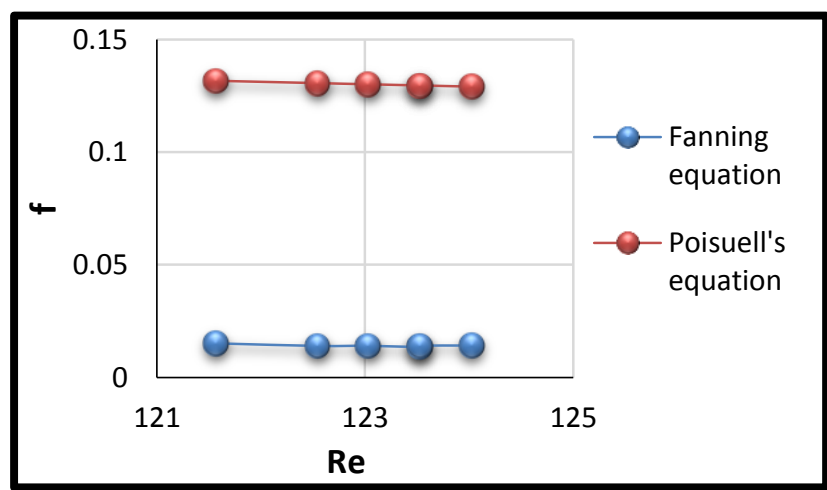

Figure 10. Effect of $\operatorname{Re}$ on friction factor at $0.01905 \mathrm{~m}$ I.D. and $50^{\circ} \mathrm{C}$ 


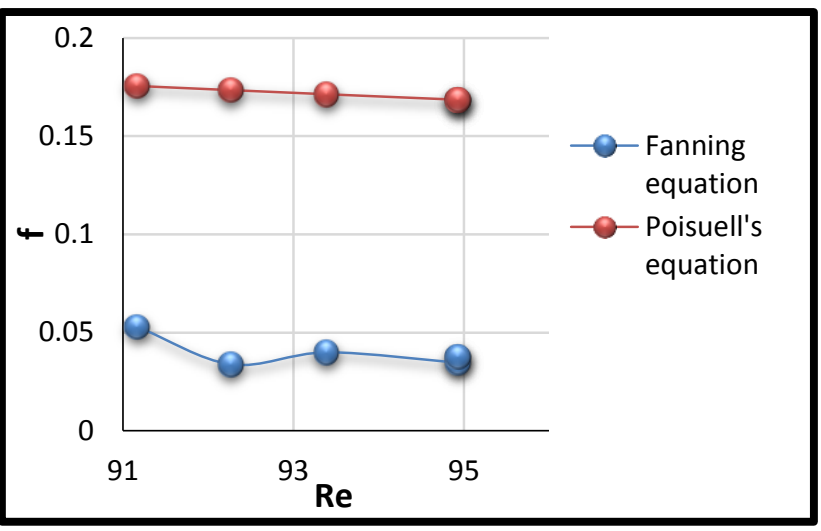

Figure 11. Effect of Re on friction factor at $0.0254 \mathrm{~m}$ I.D. and $50^{\circ} \mathrm{C}$

\section{Conclusion}

- Minimum viscosity values of $246 \mathrm{cst}$ at concentration $0.075(\mathrm{gm} / \mathrm{L}), 247 \mathrm{cst}$ at $0.075(\mathrm{gm} / \mathrm{L})$ and $242 \mathrm{cst}$ at concentrations $(0.0375,0.0625,0.075)$ of $\mathrm{CuO}$ were obtained flowing in pipes of $0.0127 \mathrm{~m} .0 .01905 \mathrm{~m}$ and $0.0254 \mathrm{~m}$ I.D. at $50^{\circ} \mathrm{C}$ respectively.

- Maximum\% Dr of $4.7269 \%$ at $0.0375(\mathrm{gm} / \mathrm{L}), 13.04 \%$ at $0.0375(\mathrm{gm} / \mathrm{L})$ $36.842 \%$ at $6.25 * 10-3(\mathrm{gm} / \mathrm{L})$ and $0.0375(\mathrm{gm} / \mathrm{L})$ of $\mathrm{CuO}$ were obtained flowing in pipes of $0.0127 \mathrm{~m} .0 .01905 \mathrm{~m}$ and $0.0254 \mathrm{~m} \mathrm{I.D.} \mathrm{at} 50^{\circ} \mathrm{C}$ respectively.

\section{Acknowledgment}

All thanks and appreciation to Petroleum Research \& Development Centre and Al-Samawah Refinery for their helping and support this research.

\section{REFERENCES}

[1] B. O. I. Anas Ghalib, Zaki Sultan,Basra Oil Institute, Amer Star, Kirkuk Oil Institute. Heavy lubricants technology [To the competenceOperation and control / second stageTechnical Diploma level]. Available: http://koti.oil.gov.iq/files/Library_Files/Refinery/Heavey\%20oil\%20techni que $\% 202$ nd $\% 20$ class.pdf.

[2] A. A. Abdulrazak, M. Al-Khatieb, and H. A. Faris, "Problems of Heavy Oil Transportation in Pipelines And Reduction of High Viscosity," Iraqi Journal of Chemical and Petroleum Engineering, vol. 16, pp. 1-9, 2015.

[3] R. M. Y. Hayder A. Abdulbari *, 2, N.H. Abdurahman1,3, A. Charles 1, "Going against the flow-A review of non-additive means of drag reduction," Journal of Industrial and Engineering Chemistry, 2012.

[4] A. Einstein, "On the motion - required by the molecular kinetic theory of heat - of small particles suspended in a stationary liquid" Annalen der Physik vol. 17 (4), 1905.

[5] S. Y. Hamedi Shokrlu, and T. Babadagli, SPE, "'Eeffects of Nano-Sized Metals on Viscosity Reduction of Heavy Oil/Bitumen during Thermal Applications" presented at the Canadian Unconventional Resources and InternationalPetroleum Conference Calgary, Alberta, Canada, October 2010.

[6] H. C. Lau, M. Yu, and Q. P. Nguyen, "Nanotechnology for oilfield applications: Challenges and impact," Journal of Petroleum Science and Engineering, vol. 157, pp. 1160-1169, 2017.

[7] J. M. B. Jie Yu, Wei Lu, Lunliang Zhang, Amy T. Kan, Ping Zhang, Erin E. Walsh, Sara N. Work, Wei Chen, James M. Tour, Michael S. Wong, Mason
B. Tomson, "Transport Study of Nanoparticles for Oilfield Application," Society of Petroleum Engineers, 2010.

[8] P. H. a. S. Shanmugam*, "Nanoparticle Characterization and Application: An Overview," Amyotroph Lateral Scler Frontotemporal Degener, vol. 18, pp. 1-103, Oct 2017.

[9] K. Amudha Murugan, Shanmugasundaram, and "Biosynthesis and characterization of silver nanoparticles using the aqueous extract of vitex negundo. ," linn. World J.Pharm. pharm. Sci., 2014.

[10] H. PATEL, "EFFECT OF NANOPARTICLES AND SOLVENT Based Emulsion On Heavy Oil Viscosity" Master Of Science, Mewbourne School Of Petroleum And Geological Engineering, University Of Oklahoma, 2016.

[11] C. R. A. Clark PD, Hyne JB, Lesage KL . AOSTRA J "Studies on the Effect of Metal Species on Oil Sands Undergoing SteamTreatments " Res., 6 (1): 53-64., 1990.

[12] H. R. Karami and D. Mowla, "Investigation of the effects of various parameters on pressure drop reduction in crude oil pipelines by drag reducing agents," Journal of Non-Newtonian Fluid Mechanics, vol. 177-178, pp. 37-45, 2012.

[13] Z. J. Li W., Qi J., " Application of nano- nickel catalyst in the viscosity reduction of Liaohe heavy oil by aquathermolysis" Journal of Fuel Chemistry and Technology, 2007.

[14] R. D. Shah, "Application of Nanoparticle Saturated Injectant Gases for EOR of Heavy Oils," SPE-129539-STU, 2009.

[15] T. Yokoyama, Masuda, H., Suzuki, M., Ehara, K., Nogi, K., Fuji, M., Fukui, T. et al. , "Basic properties andmeasuring methods of nanoparticles" in Nanoparticle technology handbook, K. N. ed. M. Hosokawa, M. Naito, T.Yokoyama, Ed., ed: Elsevier B.V., 2008, pp. 5-48.

[16] M. Haroun, Hassan, S.A., Ansari, A., Kindy, N.A., Sayed, N.A., Ali, B. and Sarma, H., "Smart Nano-EOR Process for Abu Dhabi Carbonate Reservoirs," presented at the the Abu Dhabi International Petroleum Exhibition \& Conference, Abu Dhabi, UAE, 2012.

[17] H. A. Ehsan-o-llah Ettefaghi1, Alimorad Rashidi2, Seyed Saeid Mohtasebi1 and Mahshad Alaei2, "Experimental evaluation of engine oil propertiescontaining copper oxide nanoparticles as a nanoadditive". International Journal of Industrial Chemistry, 2013.

[18] F. Bjørnseth, "Heavy Oil Production Technology Challenges and the Effect of Nano Sized Metals on the Viscosity of Heavy Oil," A literature review and an experimental study, Department of Petroleum Engineering and Applied Geophysics, Norwegian University of Science and Technology, July 2013.

[19] A. S. Srinivasan, S.N., "Surfactant-Based Fluids Containing Copper-Oxide Nanoparticles for Heavy Oil Viscosity Reduction" presented at the the SPE Annual Technical Conference and Exhibition Amsterdam, The Netherlands, 2014.

[20] M. R. E. S. Afzal, Mohammad Nikookar,A. R. Khodabandeh-Shahraki,E. Roayaeiand Amir. H. Mohammadi, " REDUCTION OF HEAVY OIL VISCOSITY USING NANOPARTICLES IN ENHANCED OIL RECOVERY PROCESS," in Enhanced Oil Recovery, A. Knight, Ed., ed: @ 2015 Nova Science Publishers, Inc., 2015.

[21] B. T. Hascakir B., Akin S., " Experimental and numerical modeling ofheavy oil recovery by electrical heating," SPE 117669, SPE/PS/CHOA InternationalThermal Operations and Heavy Oil Symposium,, 2008.

[22] W. Y. Chen Y., Lu J., Wu C., "The viscosity reduction of nano-kegginK3PMo12O40 in catalytic aquathermolysis of heavy oil" 2009.

[23] H. Sameera M.Hamad-Allah, "DRAG REDUCTION BY USING ANIONIC SURFACTANTS " Journal of Engineering vol. 15, 2009.

[24] A. Abdul-Hadi and A. A. Khadom, "Studying the Effect of Some Surfactants on Drag Reduction of Crude Oil Flow," Chinese Journal of Engineering, v3, pp. 1-6, 2013.

[25] J. E. Aristizábal-Fontal, F. B. Cortés, and C. A. Franco, "Viscosity reduction of extra heavy crude oil by magnetite nanoparticle-based ferrofluids," Adsorption Science \& Technology, vol. 36, pp. 23-45, 2017.

[26] Yunus A. Çengel, J.M.C., Fluid Mechanics: Fundamentals and Applications. 2006: McGraw-Hill Higher Education, 2006. 